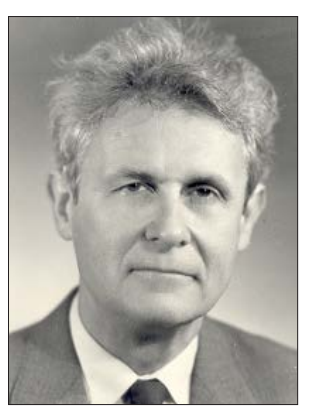

Aleksandr

P. Voinov

Воинов

Александр

Петрович

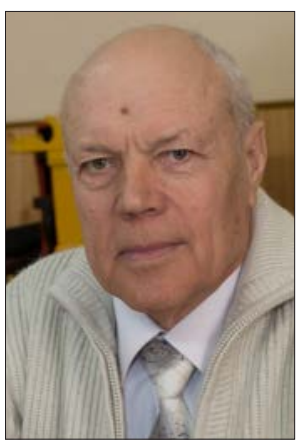

Victor

S. Samohvalov

Самохвалов

Виктор

Сергеевич

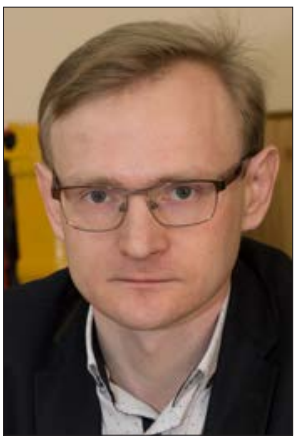

Dmytro

V. Konovalov

Коновалов

Дмитрий

Викторович

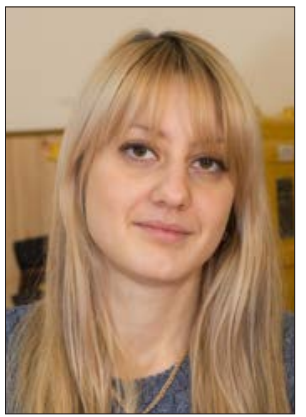

Victoria

S. Kornienko

Корниенко

Виктория

Сергеевна

УДК 621.311:621.548.005

\title{
STRUCTURE OF THE POWER ENGINEERING FUEL BALANCE IN THE UKRAINE' SHIPBUILDING AND MARINE INFRASTRUCTURE
}

\section{СТРУКТУРА ТОПЛИВНОГО БАЛАНСА ЭНЕРГЕТИКИ В СУДОСТРОЕНИИ И МОРСКОЙ ИНФРАСТРУКТУРЕ УКРАИНЫ}

DOI https://doi.org/10.15589/smi2019.1(11).15

Aleksandr P. Voinov

Victor S. Samohvalov

Dmytro V. Konovalov

Victoria S. Kornienko
Воинов Александр Петрович, докт. техн. наук, проф. voinova_s@yahoo.com ORCID ID 0000-0001-7548-4212

Самохвалов Виктор Сергеевич, доц., канд. техн. наук VSamokhvalov213@gmail.com ORCID ID 0000-0003-0264-4881

Коновалов Дмитрий Викторович, доц., канд. техн. наук, dimitriyko79@gmail.com

ORCID ID 0000-0001-7127-0487

Корниенко Виктория Сергеевна, канд. техн. наук kornienkovika1987@gmail.com ORCID ID 0000-0003-3524-2045

Admiral Makarov National University of Shipbuilding, Ukraine, Mykolaiv

Национальный университет кораблестроения имени адмирала Макарова, г. Николаев

Abstract. The aim of the researching is to formulate the problem of normalizing the structure of the fuel balance of Ukraine's power engineering sector, shipbuilding and marine infrastructure companies indicating ways to solve it. Methods of classification, induction, analogy are used. The extremely important global task facing mankind is shown to protect the environment from the increasing harmful effects on it from rapidly developing world production, especially its power engineering industry on organic fuel. The problems of the current state of the power engineering sector of Ukraine, including power plants at shipbuilding and marine infrastructure enterprises, are considered. The emerged important and complex problem of the normalization of the structure of its fuel and energy balance is highlighted and analyzed. The features of the current state of the current park of boiler equipment are highlighted. The current available directions and ways to solve the urgent and urgent problems were critically analyzed. The feasibility of reducing the share of expensive imported gas-oil fuel in the fuel and power engineering balance of domestic power engineering, in particular in the balance of shipbuilding enterprises and maritime infrastructure, is shown. The feasibility and the possibility of increasing the share of cheap domestic solid and domestic artificial gaseous fuel, the production of which is to be organized in the country, are shown. The influence of the main factors on the conditions and possibilities of solving the complex interrelated problems of the considered problem of developing the fuel and power engineering balance of domestic power engineering and its parts in the visible perspective is shown. The most probable outlines of the development issues in Ukraine in the visible perspective of power equipment consuming organic fuel are outlined. The strategic importance is shown in the broad perspective of the development in the country of a comprehensive large-scale use of domestic solid fuel as the main prospective and reliable source of energy. It was noted that the transfer of a gas-oil fuel boiler system to solid fuel is a relatively complex scientific and organizational-technical problem, which is not always amenable to an acceptable solution for a number of reasons. The importance of the quality of the process of managing the formulation, organization and implementation of a comprehensive program for the development of energy including shipbuilding and marine infrastructure power plants, based on organic fuel, in all elements of this program, was emphasized.

Key words: solid fuel, gas fuel oil, boiler, shipbuilding, natural environment, world power engineering. 
Анотація. Метою дослідження є формулювання проблеми нормалізації структури паливного балансу енергетики України, підприємств суднобудування та морської інфраструктури, пропозиція доцільних шляхів iї вирішення. Використано методи класифікації, індукції, аналогії. Показано виключно важливе глобальне завдання перед людством захисту навколишнього природного середовища від посиленого шкідливого впливу на нього з боку світового виробництва, яке інтенсивно розвивається, особливо його енергетичної галузі на органічному паливі. Розглянуто проблематику нинішнього стану енергетики України, в тому числі енергоустановок на підприємствах суднобудування та морської інфраструктури. Виділено та проаналізовано важливу і складну проблему нормалізації структури паливно-енергетичного балансу енергетики України. Виділено особливості нинішнього стану діючого парку котельного обладнання. Критично проаналізовано сучасні доступні напрями та шляхи вирішення поставлених гострих і невідкладних завдань проблеми. Показана доцільність зниження частки дорогого імпортного газо-мазутного палива в паливно-енергетичному балансі вітчизняної енергетики, зокрема в балансі підприємств суднобудування та морської інфраструктури. Показана доцільність і можливість збільшення частки дешевого вітчизняного твердого, а також вітчизняного штучного газоподібного палива, виробництво якого належить організувати в країні. Відзначено вплив основних факторів на умови та можливості вирішення складних взаємопов'язаних завдань цієї проблеми розвитку паливно-енергетичного балансу вітчизняної енергетики та іiі частин у видимій перспективі. Окреслено найбільш ймовірні контури проблематики розвитку в Україні енергетичного обладнання, яке споживає органічне паливо. Показано стратегічне значення в широкій перспективі розвитку в країні комплексного широкомасштабного використання вітчизняного твердого палива як основного перспективного і надійного джерела енергії. Відзначено, що переведення котельних установок, які працюють на газо-мазутному паливі, на тверде паливо являє собою відносно складну наукову й організаційно-технічну задачу, яка не завжди піддається прийнятному вирішенню. Наголошено на важливості якості процесу управління постановкою, організацією і здійсненням комплексної програми розвитку енергетики, в тому числі енергоустановок суднобудування та морської інфраструктури, на органічному паливі у всіх елементах цієї програми.

Ключові слова: тверде паливо, газо-мазутне паливо, котельна установка, суднобудування, природне середовище, світова енергетика.

\section{References}

[1] Korchevoy, Yu.P. (2009). Stan i perspektivi rozvitku tverdopalivnoyi energetiki Ukrayini [State and prospects of development of solid fuel energy of Ukraine]. Teplova energetika - novi vikliki chasu / Za zag. redaktsiyeyu P. Omelyanovskogo, Y. Misaka. Lviv: NVF “Ukrayinski tekhnologiyi”, pp. 29-35. [in Ukrainian].

[2] Linev, B.I., Rubinshteyn, Yu.B. (2011). Rol’ uglya v proizvodstve elektroenergii v mire [The role of coal in the production of electricity in the world]. FGUP "Institut obogashcheniya tverdogo topliva". Retrieved from: http://www.iea.org/media/workshops/2011/ccsrussia/Clean_Coal_RUS.pdf.

[3] Kanayev, A.A., Kopp, I.Z. (1989). Vzaimodeystviye energetiki i okruzhayushchey sredy [Interaction of power engineering and environment]. Leningrad: Znaniye. [in Russian].

[4] Ekologicheskiye problemy energetiki [Environmental problems of power engineering] (1989). / Otv. red. A.A. Polchina. Novosibirsk: Nauka. Sib. Otdeleniye. [in Russian].

[5] Voinov, A.P., Voinova, S.A. (2018). Upravleniye zashchitoy atmosfernogo vozdukha ot zagryazneniya energoustanovkami na tverdom toplive [Control of the protection of atmospheric air from contamination by power plants on solid fuel]. Energetika ta elektrifikatsiya, No 6, pp. 25-28. [in Russian].

[6] Gut, P.O., Klub, M.V. (2009). Osoblivosti pidgotovki ta spalyuvannya paliva [Features of fuel preparation and combustion] (dosvid VAT “Zakhidenergo"). Teplova energetika - novi vikliki chasu / Za zag. redaktsiyeyu P. Omelyanovskogo, Y. Misaka. Lviv: NVF “Ukrayinski tekhnologiyi”, pp. 89-98. [in Ukrainian].

[7] Maystrenko, O.Yu., Chernyavskiy, M.V., Kosyachkov, O.V. (2009). Rozvitok tekhnologiy gazifikatsiyi vugillya za rakhunok vikoristannya bagatostadiynikh metodiv yogo termichnoyi pererobki [Development of coal gasification technologies through the use of multistage methods for its thermal processing]. Teplova energetika - novi vikliki chasu / Za zag. redaktsiyeyu P. Omelyanovskogo, Y. Misaka. Lviv: NVF “Ukrayinski tekhnologiyi”, pp.99-104. [in Ukrainian].

[8] Maystrenko, O.Yu., Topal, O.I., Gaponich, L.S. (2009). Tekhnologiyi spalyuvannya i gazifikatsiyi vugillya u kiplyachomu i tsirkulyuyuchomu kiplyachomu shari pid tiskom dlya parogazovikh ustanovok na tverdomu palivi [Technologies for combustion and gasification of coal in a boiling and circulating fluidized bed under pressure for solid fuels for steam and gas installations]. Teplova energetika - novi vikliki chasu / Za zag. redaktsiyeyu P. Omelyanovskogo, Y. Misaka. Lviv: NVF “Ukrayinski tekhnologiyi”, pp. 269-274. [in Ukrainian].

[9] Simkin, B.E., Naumchak, V.S., Demchenko, V.I., Sokolov, A.T., Polivenok, V.A., Sidorov, Yu.M., Lavriv, L.L., Chishinskiy, M.F., Shchukin, P.V., Kozitskiy, B.D., Bilous, Yu.V. (2009). Rekonstruktsiya ASU TP elektrostantsiy Ukraini. Teplova energetika - novi vikliki chasu [Reconstruction of automated control system of power plants of Ukraine] / Za zag. redaktsieyu P. Omelyanovskogo, Y. Misaka. Lviv: NVF “Ukrayinski tekhnologiyi”, pp. 501-510. [in Russian]. 
Постановка задачи. Процесс развития человечества сложен и многогранен, характеризуется получением результатов разного рода и качества. Наряду с получением блистательных, эпохальных результатов, решений возникают и негативные последствия использования отдельных полученных решений.

В течение последних двух столетий было создано мировое производство, обеспечивающее существование и развитие человечества и построение базы для последующего прогрессивного его развития в будущем. В том числе была создана энергетическая база производства, в частности, энергопредприятия судостроения и морской инфраструктуры.

В историческом процессе своего развития человечество столкнулось с необходимостью решения множества задач разного характера, различного содержания и объёма, разной актуальности и разной степени сложности. С течением времени усложнение задач привело к формированию комплекса серьёзных, сложных проблем. Среди них своим значением выделяется проблема спасения природной среды (ПС) от гибели под вредным, все более агрессивным воздействием развивающегося мирового производства, её энергетической отрасли, в частности, энергопредприятий судостроения и морской инфраструктуры.

Анализ последних исследований и публикаций. Важно отметить, что степень вредного воздействия на ПС разных отраслей мирового производства разная. Наиболее агрессивным является многостороннее, представленное всеми разделами физики, воздействие мировой энергетики, её стационарной и транспортной частей [1-3]. Оказалось, что энергетика и в её составе энергопредприятия судостроения и морской инфраструктуры - наиболее развитая, важная и полезная для человечества техническая отрасль является одновременно наиболее агрессивной, опасной по отношению к ПС, к живой природе, в том числе к человечеству [4].

Выделение не решённых ранее частей общей проблемы. Состояние ПС, неживой природы и живой природы непрерывно ухудшается. Есть основание считать, что точка возврата её к исходному состоянию пройдена. Стоит глобальная задача добиться компенсации действующего вредного воздействия.

Сложившееся угрожающее состояние ПС, неотложная необходимость принятия срочных глобальных мер по её защите сформировали наиболее важную и сложную проблему среди стоящих перед человечеством проблем современности.

Таким образом, сформировалась глобальная проблема спасения ПС от грозной опасности, надвигающейся со стороны возрастающего вредного воздействия бурно развивающейся мировой энергетики. Острота проблемы нашла отражение, в частности, в документах мирового значения: в Киотском протоколе 1997 года по сокращению выброса парниковых газов и в Парижском соглашении по сокращению концентрации $\mathrm{CO}_{2}$ в атмосфере.
В Украине в производственной базе государства энергетика занимает важное место, является базовой отраслью. Среди частей отечественной энергетики важное место принадлежит энергетическим объектам судостроительной отрасли и морской инфраструктуры. Существенное значение хозяйственного и оборонного аспектов функционирования этой части отечественной энергетики очевидно.

Цель исследования - формулирование проблемы нормализации структуры топливного баланса энергетики Украины, в том числе энергопредприятий судостроения и морской инфраструктуры, указание путей её решения.

Методы, объект и предмет исследования. Объектом исследования служит структура топливноэнергетического баланса энергетики Украины. Предметом исследования является комплекс мероприятий по нормализации структуры топливно-энергетического баланса. Использованы методы классификации, индукции, аналогии.

Основной материал. Как известно, в энергетике, работающей на органическом топливе, используют топливо трёх видов: твёрдое, жидкое и газообразное. При этом основным является твёрдое топливо (ТT). Основную часть используемого в энергетике ТТ составляет ископаемое топливо: торф, бурый уголь, каменный уголь, антрацит, горючий сланец.

В разведанных запасах топлива на территории Украины на долю ТТ приходится около 95\%, на долю жидкого топлива - около $2 \%$, на долю газообразного - около $3 \%$.

В Украине в структуре топливно-энергетического баланса энергетики на органическом топливе дешёвое отечественное ТТ составляет лишь около $55 \%$, природный газ - около 40\%, мазут - около 5\%. При этом используемый природный газ на $80 \%$ - импортный, мазут - импортный. Отметим, что цена импортного топлива непомерно высока по сравнению с ценой отечественного топлива.

Отметим, что в тепловом балансе отечественной энергетики доля теплоты, получаемой от сжигания весьма дорогого импортного топлива, слишком высока. Это недопустимо осложняет экономическую и организационно-техническую обстановку в топливно-энергетическом комплексе и в производственной сфере государства в целом. Это негативно отражается на условиях и показателях работы не только энергетики, но и всех отраслей производства, в частности, горнодобывающей отрасли, машиностроения, судостроения, железнодорожного и водного транспорта, объектов судостроения и морской инфраструктуры, сельского хозяйства, жилищно-коммунальной сферы и так далее.

В связи с изложенным сформировалась важная, острая, трудная и неотложная проблема нормализации структуры топливно-энергетического баланса энергетики (далее - Проблема нормализации) на органическом топливе. Проблема имеет государственный уровень важности. Решение проблемы должно 
привести к разрешению сложившегося несоответствия между потребностями энергетики и реальными возможностями их удовлетворения. Это определяет чрезвычайную актуальность рассматриваемой проблемы.

Возникла необходимость разработки и осуществления на государственном уровне программы мероприятий по решению задач проблемы.

Сущность проблемы нормализации состоит в исключении сопряжённых факторов, обусловивших её возникновение и действие. Факторов два следующих:

- первый фактор - высокая цена импортного жидкого и газообразного (газо-мазутного) топлива,

- второй фактор - большая доля импортного топлива в топливно-энергетическом балансе энергетики.

Возможное реальное решение задач проблемы состоит в изыскании и использовании доступных путей и средств для ослабления и исключения влияния указанных двух тесно сопряжённых факторов.

Анализ сложившейся обстановки свидетельствует о высокой степени сложности, масштабности, государственной важности указанных задач и особенно их сочетания в целом.

Ныне в условиях сложившейся обстановки решение проблемы возможно на основе нормализации структуры топливного баланса предприятий отрасли, в частности энергопредприятий судостроения и морской инфраструктуры, путём вытеснения из него дорогостоящего импортного газо-мазутного топлива. Для этого необходимо решить две сложные комплексные задачи.

Рассмотрим основные аспекты этих задач.

Первая задача - последовательное вытеснение из топливного баланса энергетики дорогостоящего импортного газо-мазутного топлива недорогим отечественным твёрдым топливом.

Решением рассматриваемой первой задачи является перевод части котельных, работающих на газомазутном топливе, на сжигание твёрдого топлива.

Следует отметить, что в рамках данной задачи основной интерес и значительную сложность представляет сопоставительный анализ технических характеристик и ранжирование рассматриваемой группы газо-мазутных котельных по содержанию и очерёдности работ в программе перевода их на твёрдое топливо.

В этом отношении учёту и всестороннему анализу подлежит ряд вопросов: свойства и особенности каждого газо-мазутного котла, установленного в котельной, прежде всего следующие:

- тип,

- единичная тепловая мощность,

- остаточный ресурс,

- место расположения промплощадки котельной в населённом пункте,

- возможность и степень удобства создания твёрдотопливной и золо-шлаковой инфраструктуры на промплощадке котельной,
- расстояние котельной от жилых зданий и транспортных коммуникаций микрорайона расположения котельной в населённом пункте и другие.

Перевод котельных на твёрдое топливо требует тщательного анализа прогнозируемой экологической обстановки в районе расположения котельной. Проектные уровни выброса и сброса вредных веществ, особенно выброса золы, в районе расположения котельной после перевода её на твёрдое топливо не должны превышать предельно допустимых значений [5].

Уровень технологической эффективности котлов в высокой степени зависит от качества сжигаемого твёрдого топлива и стабильности его свойств во времени. При этом уровень чувствительности к качеству топлива тем выше, чем ниже единичная тепловая мощность котла. Эти важные обстоятельства требуют обеспечить повышение уровня производственной культуры в сфере подготовки и поставки потребителям твёрдого топлива. Кондиционирование твёрдого топлива, в том числе по гранулометрическому составу, является обязательным элементом подготовки сортового товарного твёрдого топлива.

Приведённые вопросы - сложная комплексная научная и организационно-техническая задача, требующая системного подхода к её решению в рамках заданных содержания, объёма, качества и сроков выполнения работ по переводу на твёрдое топливо, а также объёма предстоящих ресурсовложений.

Анализ сложившейся обстановки показывает, что степень научно-технической готовности отечественной энергетики и других отраслей производства к решению первой задачи может быть оценена как хорошая. При этом необходимо и важно обеспечить надлежаще высокий профессиональный потенциал кадров исполнителей всех административных, должностных уровней.

Важно отметить тот факт, что задача перевода газо-мазутной котельной на твёрдое топливо весьма сложна во всех отношениях. Перевод может оказаться целесообразным в ограниченном числе случаев. При этом чаще всего котельная нуждается не в модернизации, а в реконструкции или техническом перевооружении.

Строительство в Украине новых котельных разной единичной тепловой мощности в значительной степени должно опираться на применение твёрдого топлива. При этом, в частности, целесообразно широко применять котельно-топочные системы низкотемпературного псевдоожиженного (кипящего) слоя (пузырькового, циркуляционного), способные высокоэффективно использовать низкокачественное твёрдое топливо. Эти положения приобрели нормативный характер и достойны пристального внимания.

Условия предстоящего решения рассматриваемых здесь задач проблемы нормализации структуры топливного баланса усложняет необходимость решения задач обострившейся проблемы обновления изношенного оборудования энергетических установок. Особо сложной является проблема обновления парка 
котлов (60 тысяч агрегатов), более 95\% которых отработало 1,5-2,5 ресурса.

Вторая задача - последовательное вытеснение из топливного баланса энергетики дорогостоящего импортного газо-мазутного топлива недорогим отечественным (искусственным) газообразным топливом.

Здесь следует указать на то важное обстоятельство, что в принципе возможное использование отечественного недорогого природного газа вместо дорогого импортного газо-мазутного топлива следует считать средством временным и вспомогательным. Это объясняется тем, что весьма скромные (по сравнению с колоссальными запасами отечественного твёрдого топлива) запасы природного газа в Украине делают целесообразным использование его в качестве ценнейшего ископаемого химического сырья для ряда отраслей отечественного производства, а не в качестве топлива.

Проводимые НИИ угольных энерготехнологий НАН Украины научно-технические изыскания и организационно-технические разработки в промышленности приближают начало промышленного производства и появление на рынке отечественных продуктов пиролиза твёрдого топлива - искусственного газообразного топлива и искусственного жидкого (дизельного) топлива. Актуальной также является разрабатываемая технология получения газа пиролиза твёрдого топлива в кипящем слое под давлением для перспективных парогазовых энергетических установок [6-8].

Кроме этого, возможно предстоящее увеличение добычи природного газа морскими платформами на шельфе Чёрного моря.

Эти источники газообразного топлива - искусственного и естественного - приобретают черты фундаментальности и долговечности. При надлежащем успешном их развитии существующая ныне потребность импорта газо-мазутного топлива может выродиться, что чрезвычайно важно.

Доступные государственные возможности следует активнее направлять также на развитие добычи шахтного метана и производства биогаза из отходов сельскохозяйственного производства. Единичные подобные действующие источники дешёвого газообразного топлива успешно работают на территории Украины. При увеличении числа подобных источников шахтного метана и биогаза они, в районе их расположения, в состоянии обеспечить газо- и теплоснабжение потребителей малой и средней тепловой мощности.

Объективная степень научно-технической готовности науки, энергетики и других отраслей производства к решению этой второй задачи может быть оценена как удовлетворительная.

Определённые сложности в процессе решения второй задачи можно ожидать в отношении решения ряда частных задач, особенно в связи с необходимостью создания новой отрасли производства столь же важной, сколь и сложной во всех отношениях. При этом, однако, организуемое промышленное производство искусственного газообразного топлива явится крупным достижением инновационного характера и государственного уровня важности. Оно обеспечит получение крупного позитивного комплексного эффекта в энергетике и в отечественном производстве в целом.

В решении второй задачи рассматриваемой проблемы доступно использование ещё одного пути: добычи газообразного топлива, а именно газа подземной газификации твёрдого топлива, согласно идее Д.И. Менделеева.

Как известно, в 1934 году на Донбассе была сооружена и успешно испытана первая в мире натурная установка подземной газификации твёрдого топлива. На основе полученных положительных результатов в Подмосковном буроугольном бассейне было организовано широкое промышленное производство газообразного топлива трестом «Мосподземгаз». Его использовали потребители Подмосковья вплоть до замены его в 60-х годах природным газом.

Организация добычи в Украине в промышленном масштабе газа подземной газификации твёрдого топлива явится научно- и организационно-техническим достижением государственной важности. Для реализации данной возможности в промышленном масштабе необходимы весьма крупные ресурсовложения, недоступные в настоящее время. Однако научно-технические изыскания по данной важной технической задаче необходимо в нарастающем темпе проводить и всесторонне развивать. Инновационное качество данной задачи очевидно.

По соображениям сбережения природной окружающей среды добыча газообразного топлива в виде сланцевого газа на территории Украины должна быть категорически запрещена.

Отметим, что перевод части действующих котельных с импортного природного газа на существенно менее дорогое отечественное газообразное топливо, полученное из твёрдого топлива, является по существу фактом косвенного вытеснения импортного газа отечественным твёрдым топливом. В этом состоит идея постановки и решения второй из рассмотренных выше задач.

Результат использования возможностей решения каждой из рассматриваемых двух задач в конкретной производственной отрасли, районе территории по времени будет разным. Он будет определяться в каждом случае сочетанием комплекса конкретных условий и действующих факторов. Важно то, что при оптимальном их выборе результат будет позитивным и значительным.

Программа нормализации структуры топливного баланса энергетики отличается высоким уровнем значимости, сложности и комплексным характером; её успешное решение должно опираться на комплексно-системный подход.

Проблема нормализации структуры топливного баланса является частью аналогичной проблемы 
развития энергетики. В рамках последней предстоящее обновление изношенного оборудования тепловых электрических станций (ТЭС) будет опираться на замену паросилового цикла парогазовым циклом. В парогазовых установках (ПГУ) будущего, в их газотурбинной части предстоит сжигать отечественное газообразное топливо. Его получение целесообразно организовать путём решения двух задач, рассмотренных выше. Ocложняющим обстоятельством является необходимость решения задач рассматриваемой проблемы параллельно с решением задач других неотложных проблем, в частности, проблемы обновления изношенного оборудования энергетических установок. Эти обстоятельства относятся также к развитию энергетики в судостроении и морской инфраструктуре.

Далее. Решение комплекса задач программы нормализации структуры топливно-энергетического баланса энергетики может быть успешным только при соблюдении ряда важных условий. В их числе одним из основных является условие обеспечения (осуществления) высококачественного управления процессом разработки программы, практического осуществления содержащихся в ней мероприятий, контроля получаемых результатов, их критического анализа и оценки.

Практическая реализация этого условия представляет собой столь же важную, сколь и сложную научную и организационно-техническую задачу.

Согласно функциональному назначению, Программа нормализации должна воздействовать на многочисленные производственные объекты, связанные с производством и с потреблением энергии (электричества и теплоты). Эти объекты сформировали в государстве многоуровневую иерархическую административно-информационную пирамиду, внутри которой между ними действуют многочисленные управляющие связи. Каждый объект - элемент пирамиды - получает управляющее воздействие от определённого объекта более высокого уровня. Управляет он объектами нижестоящих уровней.

Уровень эффективности работы действия подобной производственной системы (её информационной модели - пирамиды) определяется режимом её функционирования в конкретных существующих условиях протекания технологического процесса. А режим функционирования производственного (или модельного - информационного) объекта задаётся системой автоматизированного управления (АСУ) этим объектом. Важно отметить, что, чем выше качество процесса управления, тем выше поддерживаемый АСУ уровень эффективности функционирования управляемого ею объекта.

Таким образом, в конечном счёте, уровень эффективности функционирования рассматриваемой здесь производственной системы определяется качеством процесса воздействия на неё со стороны автоматизированной системы управления технологическим процессом (АСУ ТП) этой системы.

Следовательно, аналогично уровень эффективности осуществления Программы нормализации будет зависеть от качества процесса воздействия на неё АСУ ТП высшего (первого) уровня, стоящего над всеми участниками Программы: министерствами, учреждениями центрального подчинения. Этой первой (главной) АСУ ТП будут подчинены все другие АСУ ТП, ранжированные по их месту (уровню) в информационной пирамиде Программы нормализации.

Эта новая по назначению АСУ ТП дополнит парк АСУ ТП, широко применяемых в отечественной энергетике [9].

Обсуждение полученных результатов исследования. Предстоящие нормализация структуры топливного баланса энергетики и обновление парка действующих автоматизированных котельных установок будут активно способствовать повышению уровня их технологической эффективности функционирования, то есть повышению уровня её составляющих: экологической, экономической и общетехнической эффективности. При этом важно отметить, что повышение экологичности котлов - наиболее активных источников опасного загрязнения атмосферы - будет иметь большое значение. Реализации данного технологического эффекта будут способствовать системы автоматического управления котельными установками.

Следует особо отметить то важное обстоятельство, что реализация программы вытеснения импортного газо-мазутного топлива из структуры топливного баланса отрасли возможна при использовании комплексно-системного подхода, всех его аспектов.

Необходимо указать на то, что рассматриваемая Программа нормализации может быть реализована только при условии надлежащего научно-технического обеспечения всех её частей, разделов и элементов. Среди условий реализации важнейшим условием является высокий кадровый потенциал прямых и косвенных исполнителей работы над Программой. При этом, как известно, качество выполняемых заданий зависит от уровня профессиональной квалификации исполнителя и уровня их социальной ответственности. Отечественная энергетика, в том числе энергетика судостроения и морской инфраструктуры, располагает подобным кадровым потенциалом.

При формировании Программы нормализации необходимо отразить все возрастающие современные требования мирового научно-технического прогресса. Принимаемые в Программе решения любого характера должны быть в возможно большей степени инновационно насыщенными. В перспективе только такие решения будут удовлетворять высоким требованиям, предъявляемым к энергетике - передовой отрасли производства.

\section{ВЫВОДЫ}

1. Перед человечеством стоит проблема защиты природной среды от непомерно высокого, возрастающего с ускорением вредного воздействия производства.

2. Среди отраслей мирового и отечественного производства наиболее сильное вредное, комплексное воздействие на природную среду оказывает энергетика. 
3. Сложившееся критическое состояние природной среды, неотложная необходимость принятия срочных глобальных мер по её защите сформировали наиболее важную и сложную проблему современности - проблему спасения природной среды. В условиях Украины, в частности, в энергоустановках судостроительных предприятий и морской инфраструктуры, острота проблемы высока.

4. В структуре топливно-энергетического баланса энергетики Украины доля отечественного недорогого твёрдого топлива составляет около $63 \%$; около $37 \%$ составляет доля непомерно дорогого импортного газо-мазутного топлива. Цена электричества и теплоты весьма высока, что существенно осложнило экономическую обстановку в производстве и в обществе.

5. Сформировалась проблема нормализации структуры топливно-энергетического баланса энергетики, всех её частей, имеющая государственный уровень важности и неотложности. Решение проблемы возможно путём решения двух задач.

6. Первая задача - вытеснение из топливно-энергетического баланса энергетики дорогого импортного газо-мазутного топлива дешёвым отечественным твёрдым топливом.

7. Вторая задача - вытеснение из топливно-энергетического баланса энергетики дорогого импортного газо-мазутного топлива дешёвым отечественным искусственным газообразным топливом.

8. Решение задач рассматриваемой проблемы усложнено необходимостью параллельно решать задачи других неотложных проблем, в частности, проблемы обновления изношенного оборудования отечественных энергетических установок, особенно парка котлов.

9. В сфере сжигания твёрдого топлива целесообразно решительно расширять применение котельно-топочной технологии низкотемпературного кипящего слоя, позволяющей высокоэффективно сжигать предельно низкокачественное твёрдое топливо.

10. Стратегически важной государственной задачей является организация в стране и ввод в действие промышленного производства искусственного газообразного топлива - газа пиролиза твёрдого топлива и газа подземной газификации твёрдого топлива.

11. В процессе постановки и выполнения Программы нормализации необходимо большое внимание уделить задачам управления работой её модельной многоуровневой информационной пирамиды и управления функционированием реального комплекса многочисленных производственных объектов, в котором эта программа воплощается.

12. Принимаемые в Программе нормализации решения должны опираться на комплексно-системный подход и на применение прогрессивных, инновационно насыщенных научно- и организационно-технических решений.

13. Нормализация структуры топливного баланса энергетических установок, в том числе установок судостроительных предприятий и объектов морской инфраструктуры, - важное условие повышения уровня технологической эффективности, в том числе повышения уровня их экологической эффективности.

14. Нормализация структуры топливно-энергетического баланса энергетики - необходимое условие решительного повышения уровня эффективности функционирования отечественного топливно-энергетического комплекса, в том числе оборудования энергетических установок в судостроении и в морской инфраструктуре.

15. Программа нормализации является важным разделом программы развития энергетической отрасли Украины. Это явится крупным вкладом в развитие энергетики и отечественного производства в целом.

\section{Список литературы}

[1] Корчевой Ю.П. Стан і перспективи розвитку твердопаливної енергетики України. Теплова енергетика нові виклики часу / За заг. редакцією П. Омеляновського, Й. Мисака. Львів : НВФ «Українські технології», 2009. C. 29-35.

[2] Линев Б.И., Рубинштейн Ю.Б. Роль угля в производстве электроэнергии в мире. ФГУП «Институт обогащения твёрдого топлива». 2011. URL: http:/www.iea.org/media/workshops/2011/ccsrussia/Clean_Coal_RUS.pdf.

[3] Канаев А.А., Копп И.З. Взаимодействие энергетики и окружающей среды. Ленинград : Знание, 1989.

[4] Экологические проблемы энергетики / Отв. ред. А.А. Полчина. Новосибирск : Наука, Сиб. Отделение. 1989.

[5] Воинов А.П., Воинова С.А. Управление защитой атмосферного воздуха от загрязнения энергоустановками на твердом топливе. Енергетика та електрифікаиія, 2018. № 6. С. 25-28.

[6] Гут П.О., Клуб М.В. Особливості підготовки та спалювання палива (досвід ВАТ «Західенерго»). Теплова енергетика - нові виклики часу / За заг. редакцією П. Омеляновського. Й. Мисака. Львів : НВФ «Українські технології», 2009. С. 89-98.

[7] Майстренко О.Ю., Чернявський М.В., Косячков О.В. Розвиток технологій газифікації вугілля за рахунок використання багатостадійних методів його термічної переробки. Теплова енергетика - нові виклики часу / За заг. редакцією П. Омеляновського. Й. Мисака. Львів : НВФ «Українські технології», 2009. С. 99-104.

[8] Майстренко О.Ю., Топал, О.І., Гапонич Л.С. Технології спалювання і газифікації вугілля у киплячому і циркулюючому киплячому шарі під тиском для парогазових установок на твердому паливі. Теплова енергетика - нові виклики часу / За заг. редакцією П. Омеляновського. Й. Мисака. Львів: НВФ «Українські технології», 2009. С. $269-274$.

[9] Симкін Б.Е., Наумчак В.С., Демченко В.І., Соколов А.Т., Полівенок В.А., Сідоров Ю.М., Лаврів Л.Л., Чишинський М.Ф., Щукін П.В., Козицький Б.Д., Білоус Ю.В. Реконструкція АСУ ТП електростанцій України. Теплова енергетика - нові виклики часу / За заг. редакцією П. Омеляновського. Й. Мисака. Львів : НВФ «Українські технології», 2009. С. 501-510. 